\title{
Dynamics Online Course: A Challenge content delivered with best teaching practices keeps students engaged
}

\section{Dr. Carmen M Muller-Karger, Florida International University}

Instructor at the Mechanical Engineering Department at Florida International University since 2016. With a Bachelor's degree in Mechanical Engineering, an MSc in Mechanical Engineering in the area of Rotodynamics from the University of Virginia and a Ph.D. in Engineering Science in the area of Biomechanics from the Central University of Venezuela. Main interest in Simulation on Mechanical Engineering, Biomechanics, Motion Analysis, Finite Element Analysis, Mechanical Medical Devices Design. Highly interested in Higher Education Curriculum Design, Academic Leadership, and teaching and classroom innovation.

\section{Dr. Lili Steiner, Florida International University}

I design and implement education solutions that are efficient, effective, and scalable. Specifically, I focus on the development of meaningful learning innovation from discovery and design through production and deployment. My research and experience have shown that a full-cycle approach is the most effective way to deliver value. Because of this, I work on full-cycle, full-scale projects. Conceptually, this means that I'm involved in every phase rather than just research and design: I deliver fully functional, sustainable systems. The way I achieve this is by taking an approach that is methodologically flexible and peoplefocused. Education innovation is as much about the solution as it is about managing change. So no matter how cutting-edge technology, my process incorporates strategic planning, instructional design best practices, and stakeholder involvement. I'm deliberate about tapping into community know-how and creating collaborative optimal solutions that take into account the often-intangible but always-essential human element. Got my bachelor's degree in Computer Science Engineering at the Universidad Simón Bolívar, Caracas- Venezuela, M.Sc. in Instructional Technologies and Distance Education at Nova Southeastern Education, and an Ed D in Instructional Design and Technology at Nova Southeastern University. If you want to learn more about my work, go to http://www.lilisteiner.com/ 


\title{
Dynamics Online Course: A Challenge content delivered with best teaching practices keeps students engaged
}

\begin{abstract}
Dynamics is a core course in the mechanical and civil engineering programs; and, because of its complexity, this course continues to represent one of the main challenges facing our students. Historically, faculty were resistant to deliver the content of this course online. In order to offer an equivalent, or better yet, an improved class session experience, we pursued engagement following best practices to design this course online. Our practices include course structure, alignment of critical course components, different forms of assessment and accessibility. We structured the course very granularly based on the learning theories framework, and used instructional technologies to produce single-concept videos designed for the module topics.

The course was organized into nine modules, and the content within them was divided into short narrated lectures presenting the theoretical background and single-concept videos using LearningGlass ${ }^{\mathrm{TM}}$ were added in order to solve examples related to the mentioned theoretical framework. The advantage of the example videos is that students can watch them repeatedly the week they are released and again while doing their homework or studying for exams. Each module also provided assessed activities such as assignments and quizzes.

In the process of course design, we used a backward design framework, which helped us gain a clear idea of the students' learning outcomes and the ABET outcomes. As a result, we were able to revisit and refine the course learning objectives and write the specific module learning objectives. Accordingly, we reviewed and adjusted the learning activities and assessed activities, such as assignments, quizzes, exams, discussions, among others, in order to be aligned with the learning objectives. We also included well-defined expectations on every assessed activity by establishing clear criteria using rubrics for all evaluated activities.

Last but not least, by using accessibility features in all the course elements, we were able to successfully target a diverse student population and benefit the learning community as a whole. This paper will also provide the highlights and the rationale behind the selection of these educational technology tools and determine how they foster quality course delivery. To best
\end{abstract}


illustrate course impact on students, we qualitatively and quantitatively analyzed data collected from four different sources, some of them for four consecutive terms regarding grades, students' perception, and developed skills.

\section{Introduction}

Dynamics is a core course in engineering and is usually one of the main challenges for students pursuing Mechanical or Civil Engineering Degrees at our Institution. Historically, there has been resistance by Faculty to deliver this course online due to the idea that in face-to-face courses, the instructor has more tools to teach the challenging concepts. With the new and emerging technologies, communication networks and powerful computers, the concept of distance learning has evolved and redefined the learning process [1] .

The Dynamics course is taught by the Mechanical Engineering Department, represents a main course for the Mechanical Engineering curriculum and is a service course for the Civil Engineering Department and the Electrical Engineering Department. This course is taken yearly by more than 400 students at our Institution in three terms, spring, summer and fall. During the spring and fall terms, this course is offered in four to five sections (16 weeks long) and during summer (A, 6 weeks or summer C, 12 weeks) at least two sections are offered. The sections fluctuate between 50 to 90 students, depending on the demand and classroom resources. The online version of the course is offered for one section in each spring and fall terms, and for the 12 weeks summer course.

Regarding the Mechanical Engineering curriculum at our Institution, Dynamics is a first semester sophomore course that advances statics and multivariable calculus as direct course prerequisites, and indirectly requires solid previous knowledge of mechanical physics and math concepts such as trigonometry, algebra, calculus and vectors. This course represents the gateway for many other courses in the curriculum, and in particular, a group of four subsequent courses that are prerequisites to each other in the sequence known as Transport Phenomena, Heat Transfer, Senior Design I and Senior Design II. Dynamics also represents the gateway to Mechanical Design I, Mechanical Design II and System Dynamics. In consequence, students who fail to pass Dynamics in their first attempt will automatically fall behind in their four-year graduation goal unless they retake this course during the summer session. 
As regards the Civil Engineering curriculum at our Institution, the Dynamics course is scheduled for the first term of junior year and is a prerequisite for a group of three more classes that are prerequisites to each other in the sequence of Fluid Mechanics, Geotechnical Engineering and Senior Design Project. Again, passing this course constitutes a key component in successfully graduating in four years.

For the above-mentioned reasons and as stated by several researchers in the area of engineering education [2] [3], the Dynamics course represents a major icon for both Mechanical and Civil Engineering. Success in this class will help in the student retention rate, strengthen student engineering identity, and, therefore, in student graduation success.

As distance education is becoming less of a disruption and more mainstream, the design of instruction is essential, as it is not possible to achieve these results if there is no strategy to produce equivalent (not equal) results, the transactional distance has been defined as "a psychological and communications space to be crossed, a space of potential misunderstanding between the inputs on instructor and those of the learner" [4], [5] expanded by stating that "this distance is pedagogical not geographic" and needs to be minimized by the design of instruction. The instructor's ability to communicate, form community, and deliver the appropriate lesson effectively makes all the difference in student learning outcomes. It is further suggested that the interaction that takes place between faculty and students plays a major role in the success of online learning. This interaction must be on a human level, meaning establishing a relationship and the ability to connect with students and help them to feel as a part of the class [6].

Florida International University is committed to high quality teaching by student-centered learning, and serving a very diverse population of urban local, regional and international students. This commitment translates into achieving student learning success by providing different approaches to course delivery, different teaching strategies and learning experiences. The students are offered the possibility of choosing the course format most adequate to their learning capabilities. Considering that a diverse student population attends at our Institution and a great number of them work full time and are heads of household, our Institution has fulfilled the commitment that all courses should offer at least one section online or hybrid (see figure 1), representing about $45 \%$ of the total course enrolment. 

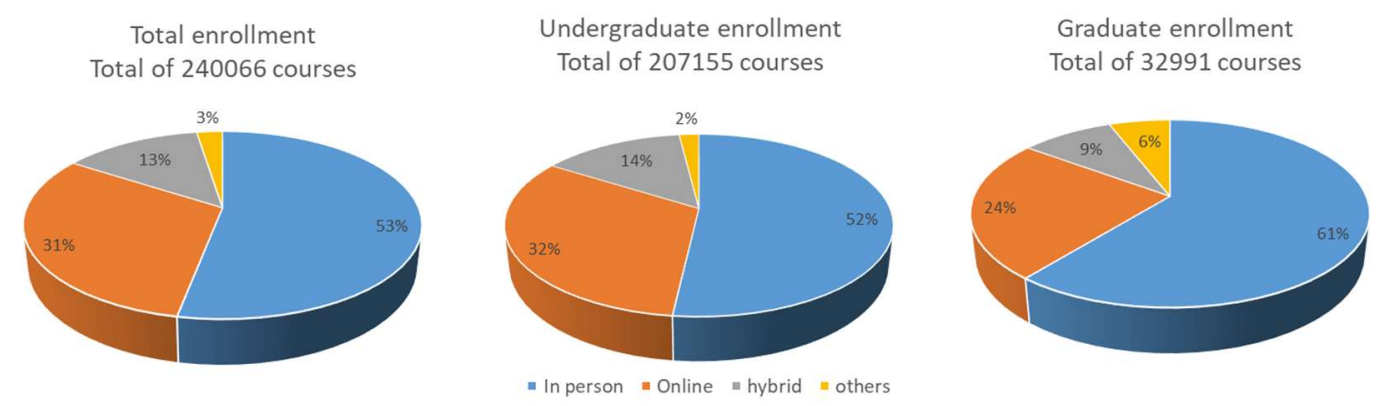

Figure 1. Total Student enrollment at our Institution during fall 2019 term, hybrid and online courses represent about 45\%. Data from Division of Information Technology, Florida

\section{International University}

There are several institution that recently have developed a dynamics online course, for example Purwar and C. A. Scott [7] describe in detail their course develpoment and delivery; they offer this course one during summer terms. There are other dynamic online courses [8] [9] but it is difficult to find information without proper registration.

In order to offer an equivalent to a face-to-face (F2F) version, or better yet, an improved class session experience, we pursued engagement following best practices to design this course. This paper describes the design process of our Dynamics online course and the qualitative and quantitative results of delivering this course during four consecutive terms. The best practices included thoughtful course structure, proper selection of instructional resources, alignment of critical course components, different forms of assessments, descriptive rubrics and accessibility.

\section{Course Description}

Dynamics is an undergraduate-level course that covers the study of motion of particles and rigid bodies by applying the vector approach. The topics include kinematics of particles and rigid bodies using different coordinate systems, which includes relative motion between objects, kinetics of particles and rigid bodies in plane motion, force and acceleration, work and energy methods, impulse and momentum methods. Since the course is intended to serve students with a background in math and physics, knowledge in math and statics are expected. 


\section{Course Objectives}

The course objectives ( $\mathrm{CO})$ are related to student outcomes. At the end of this course, students will able to:

1. Review general concepts in kinematics of particle in rectilinear motion and curvilinear motion, and particular cases of particles moving with constant acceleration and motion of a projectile.

2. Analyze general curvilinear motion of one or two particles, including dependent and relative motion, and determine the best coordinate system to use for solving problems between: rectangular component, normal and tangential components or cylindrical components.

3. Understand the kinetics of a particle by using the force and acceleration approach by analyzing Newton's second law in vectorial form, applying equations of motion using different set of components for a system of particles, and solving problems involving forces and accelerations.

4. Analyze and evaluate the kinetics of a particle by using the work and energy approach by evaluating the principle of work and energy, exploring the concept of conservative forces and conservation of mechanical energy.

5. Analyze the kinetics of a particle by using the impulse and momentum approach by evaluating the principle linear impulse and momentum, and conservation of linear momentum.

6. Apply the concept of impulse and momentum to study impact of two particles.

7. Analyze and evaluate the kinematics of rigid bodies, by evaluating translation, rotation about a fixed axis, absolute motion analysis; relative-motion analysis: velocity; instantaneous center of zero velocity; relative motion analysis.

8. Understand the kinetics of a rigid body by using the force and acceleration approach by analyzing and evaluating mass moment of inertia of a body; planar kinetic equations of motion; equations of motion for translation and for rotation about a fixed axis; equations of motion for general plane motion.

9. Analyze and evaluate the kinetics of a rigid body by using the work and energy approach by evaluating kinetic and potential energy of a rigid body; work of a force and a couple; principle of work and energy; conservation of energy. 
10. Analyze and evaluate the kinetics of a rigid body using the impulse and momentum approach by evaluating the linear and angular momentum of a rigid body; principle of impulse and momentum; conservation of momentum.

11. Analyze and calculate three-dimensional kinematics of rigid bodies subjected to rotation about a fixed point, by relative motion analysis of a rigid body using translating and rotating axes.

\section{Course Design}

The first version of the course was scheduled to be offered in the fall of 2018. The design and development time were eight weeks prior with an average of 2 hours a day to record videos. All the content in this course was developed using Universal Design principles (UX) making all resources accessible (ADA compliant).

In the process of course design, we used the Backward Design Framework (see figure 2) based on the course desired students' learning outcomes and the ABET outcomes [10], we were first able define the Course Objectives ( $\mathrm{CO}$ ) and write the specific Module Objectives (MO). The second step was to determine acceptable levels of evidence that support that the student attained the learning objectives and the third step is to design the learning activities that will make the desired results happen, consider teaching methods, sequence of the lectures and examples, and resource materials based on the knowledge and skills students will need to achieve the desired results.

Accordingly, the course instructor and the instructional designer reviewed and adjusted the learning activities and assessed activities, such as assignments, quizzes, exams, discussions in order to be aligned with the learning objectives. 


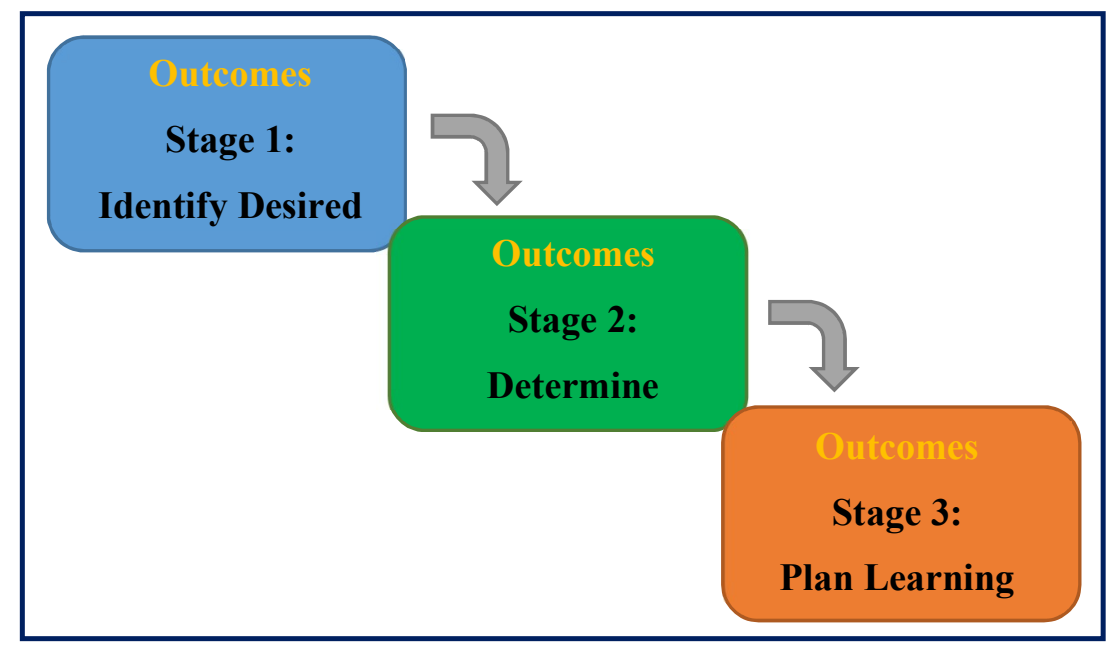

Figure 2. Backward Design Framework. [11]

\section{Course structure}

The course was organized in nine modules, each modulus representing one chapter of the textbook used for this course [12]. The first four modules introduce dynamics of particles as follows: 1.- Kinematics of particle, 2.- Kinetics of particle: Force and Acceleration, 3.- Kinetics of particle: Work and Energy, 4. Kinetics of particle: Impulse and Momentum. The following five modules introduce dynamics of rigid bodies as follows: 5.- Kinematics of Rigid Bodies (RB), 6.- Kinetics of RB: Force and Acceleration, 7.- Kinetics of RB: Work and Energy, 8.Kinetics of RB: Impulse and Momentum. The last module (9.-) Introduces the kinematics in 3D. Each module topics were explained via single concept videos; this implied that the content was divided into short narrated lecture videos presenting the theoretical background and, several single problem-solving videos using LearningGlass ${ }^{\mathrm{TM}}$ were added in order to solve examples related to the mentioned theoretical framework.

Each module includes:

1. Module Overview: this page includes the module topics' descriptions and their pertinence, the module objectives, their alignment to course objectives, and the required and optional tasks to be completed. 
2. Narrated lectures: These narrated videos are split by topics and provide the theoretical background, by design, these videos are less or equal to 25 minutes. The narrated lectures include theoretical background, application of concepts, derivation and explanation of formulas and some simple examples.

3. Power point presentation with theoretical background: These slides have the same content as the narrated lectures.

4. Videos that teach examples of solving problems: Each example video presents a detailed solution of a dynamics problem (between 10 to 15 minutes). Each module has 7 to 12 videos released with solutions to key problems and are located after the narrated lectures. The advantage of the example videos is that students can watch them repeatedly the week they are released and again while doing their homework or studying for the exams.

5. PowerPoint ${ }^{\mathrm{TM}}$ presentation with all examples without solution.

6. PowerPoint ${ }^{\mathrm{TM}}$ presentation with all examples with solution.

7. Assessed activities such as assignments and exams.

\section{Alignment of critical course components}

The term alignment is used as the "interdependence among the critical course components that ensure that students achieve the desired learning objectives for the course" [13]. Each module provides a set of specific learning objectives that are reflected on each learning or assessed activity and support the aforenoted course learning objectives (table 1). Table 2 is designed for each of the nine modules (only shown for Module 2) to align module learning objectives with assignments, learning activities, assessments, Instructional material and course tools. 
Table 1. Alignment of course learning objectives with module learning objectives (CO vs MO). [Muller (2019). EGN 3321 QM Accredited Course]

\begin{tabular}{|c|c|c|c|c|c|c|c|c|c|}
\hline \multicolumn{10}{|c|}{ COURSE TO MODULE ALIGNMENT (QM 2.1) } \\
\hline & \multicolumn{9}{|c|}{ Module Objetives } \\
\hline Course Objetives & 1 & 2 & 3 & 4 & 5 & 6 & 7 & 8 & 9 \\
\hline $\mathrm{CO} 1$ & $\mathrm{X}$ & $X$ & $\mathrm{X}$ & $\mathrm{X}$ & $\mathrm{X}$ & $\mathrm{X}$ & $\mathrm{X}$ & $\mathrm{X}$ & $\mathrm{X}$ \\
\hline $\mathrm{CO} 2$ & $\mathrm{X}$ & $\mathrm{X}$ & $\mathrm{X}$ & $\mathrm{X}$ & & $\mathrm{X}$ & $\mathrm{X}$ & $\mathrm{X}$ & $\mathrm{X}$ \\
\hline $\mathrm{CO} 3$ & & $\mathrm{X}$ & $\mathrm{X}$ & $\mathrm{X}$ & & $\mathrm{X}$ & $\mathrm{X}$ & $\mathrm{X}$ & \\
\hline $\mathrm{CO} 4$ & & & $\mathrm{X}$ & $\mathrm{X}$ & & & $\mathrm{X}$ & $\mathrm{X}$ & \\
\hline $\mathrm{CO} 5$ & & & & $\mathrm{X}$ & & & & $\mathrm{X}$ & \\
\hline $\mathrm{CO} 6$ & & & & $\mathrm{X}$ & & & & $\mathrm{X}$ & \\
\hline $\mathrm{CO} 7$ & & & & & $\mathrm{X}$ & $\mathrm{X}$ & $\mathrm{X}$ & $\mathrm{X}$ & $\mathrm{X}$ \\
\hline $\mathrm{CO} 8$ & & & & & & $\mathrm{X}$ & X & & \\
\hline $\mathrm{CO} 9$ & & & & & & & X & X & \\
\hline CO 10 & & & & & & & & X & \\
\hline $\mathrm{CO} 11$ & & & & & & & & & X \\
\hline
\end{tabular}

Table 2. Alignment of module learning objectives with assignments, learning activities, assessments, Instructional material and course tools. Example Module 2

\begin{tabular}{|c|c|c|c|c|}
\hline \multicolumn{5}{|c|}{$\begin{array}{l}\text { MODULE LEARNING OBJECTIVES, INSTRUCTIONAL MATERIALS, ACTIVITIES \& } \\
\text { TOOL ALIGNMENT (QM 2.2, 2.4, 3.1, 4.1, 5.1 \& 6.1) }\end{array}$} \\
\hline Module & $\begin{array}{l}\text { Module Learning } \\
\text { Objectives }\end{array}$ & $\begin{array}{l}\text { Assignments/ } \\
\text { Learning Activities }\end{array}$ & $\begin{array}{l}\text { Assessment } \\
\text { activities }\end{array}$ & Course Tools \\
\hline 2 & $\begin{array}{l}\text { State Newton's } \\
\text { Second Law of } \\
\text { Motion. } \\
\text { Define and } \\
\text { understand the } \\
\text { concepts mass and } \\
\text { weight. } \\
\text { Analyze particle } \\
\text { kinetics using the } \\
\text { equation of motion } \\
\text { with different } \\
\text { coordinate } \\
\text { systems. }\end{array}$ & $\begin{array}{l}\text { Read Text book. } \\
\text { Watch narrated } \\
\text { lecture with } \\
\text { theoretical } \\
\text { background. } \\
\text { Watch short videos } \\
\text { of key problem } \\
\text { solving }\end{array}$ & $\begin{array}{l}\text { Material will be } \\
\text { evaluated in first } \\
\text { midterm and final } \\
\text { exam. } \\
\text { Solve assigned } \\
\text { problems as } \\
\text { homework using } \\
\text { LTI, Pearson } \\
\text { MasteringEngineer } \\
\text { ing (10 problems) }\end{array}$ & $\begin{array}{l}\text { CANVAS } \\
\text { LTI integration from } \\
\text { textbook. Pearson } \\
\text { MasteringEngineering } \\
\text { Calculator } \\
\text { Narrated lectures and } \\
\text { solved example } \\
\text { videos. }\end{array}$ \\
\hline
\end{tabular}




\section{Selection of instructional technologies/Resources,}

The course is delivered using Canvas ${ }^{\mathrm{TM}}$ [14], a learning management system where the resources for students can be organized and delivered by choice of the instructor. This platform also allows discussion forums, grading tools with feedback to students, among other learning and communication tools. Added to all the resources produced by the instructor, the students have access to the required Mastering Engineering learning platform coupled with the e-textbook [12] that offers adaptive learning as part of the reading and problem-solving assignments.

The narrated lectures were recorded using the software ExplainEverything (TM) [15], which is a software that allows recording voice-over pdf files while doing annotations, and the instructor can prepare Khan academy style videos.

To produce the problem-solving videos, the Instructor used the recording studio with Learning Glass (TM), see Figure 3. This technique was chosen because it provides a sense of instructor presence and helps communication with the students.

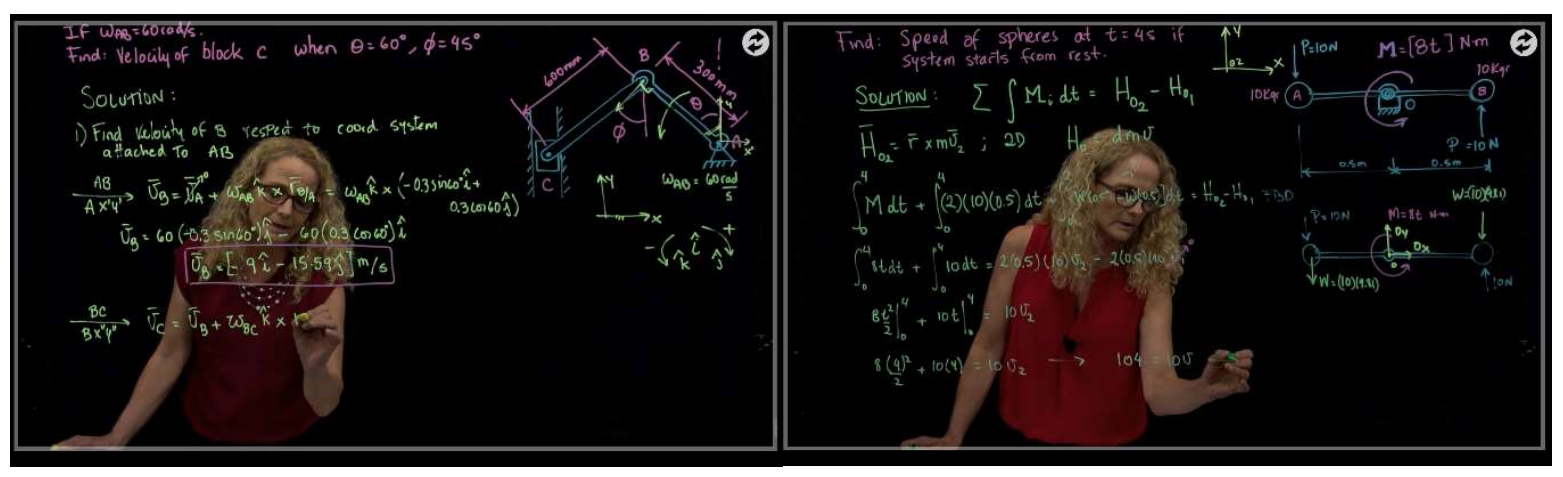

Figure 3. Learning Glass videos (screenshots)

\section{Online Course Delivery}

In order to provide a learning experience for any course, a robust design includes a predictable and consistent teaching presence. Teaching presence begins before the course commences as the instructor and the instructional designer, plan and prepare the study course, and it continues during the course, as the instructor facilitates the discourse and provides direct instruction when required [16]. Learning delivery strategies was determined by Lewis and Slapak-Barski [17] conclusions where they stated that the use of narrated materials provide a case for social agency [18] and that 
the principle of personalization helps narrated instructional messages promote an organic conversation where the role of the learner is an active participant, rather than merely a listener.

\section{Teaching Presence:}

1. Welcome video and announcement

2. Weekly Announcements to set the pace with the upcoming activities as well as weekly reminders.

3. Narrated lecture videos and single problem-solving videos.

4. Contacting students whose performance is below expectations. The instructor would then review the previous week performance feedback using the analytics provided by the LMS and the e-book publisher.

5. Online and face-to-face office hours

6. All assignments and exam solutions need to be submitted for grading and individual feedback.

\section{Student Assessment}

The course provides different forms of assessments, Table 3 shows assessment activities with percentage over total grade and Table 4 show the grading scale. The main assessments are the following:

1. Pearson's guided homework (formative assessments). Assignments included feedback in the form of tips and hints (recommended readings) that supported students to complete the homework assignment and experience a less stressful learning experience. Students have to solve an average of 10 problems weekly.

2. Exams (summative assessments- two midterm and one final) are being held at our Institution or at approved proctoring centers. The exams are delivered in computer labs also using Pearson's learning platform and students must submit handwritten solutions (scratch paper) with their work in order to have their exam graded with rubrics (table 5) that provide clear expectations for the students' exams. 
Table 3. Assessment activities and Grading weight

\begin{tabular}{|l|l|c|l|}
\hline Course requirements & Dates & $\begin{array}{l}\text { Points for } \\
\text { Each }\end{array}$ & Weight \\
\hline First Exam & Th, Oct 4 ${ }^{\text {th }}, 2018,3: 30 \mathrm{pm}-4: 45 \mathrm{pm}$ & 100 & $25 \%$ \\
\hline Second Exam & Th, Nov 8 ${ }^{\text {th }}, 2018,3: 30 \mathrm{pm}-4: 45 \mathrm{pm}$ & 100 & $30 \%$ \\
\hline Comprehensive Final Exam & Sat Dec 8 $8^{\text {th }}, 2018,2: 15 \mathrm{pm}-4: 45 \mathrm{pm}$ & 150 & $35 \%$ \\
\hline Assignments/discussion & $\begin{array}{l}\text { 9 assignments plus discussed problem } \\
\text { posted over the week. }\end{array}$ & 10 each & $10 \%$ \\
\hline Total & & & 100 \\
\hline
\end{tabular}

Table 4. Grading Structure

\begin{tabular}{|c|c|c|c|c|c|}
\hline Letter & Range \% & Letter & Range \% & Letter & Range \% \\
\hline A & 93 or above & B & $83-86$ & C & $65-73$ \\
\hline A- & $90-92$ & B- & $80-82$ & D & $50-64$ \\
\hline B+ & $87-89$ & C+ & $74-79$ & F & Under 50 \\
\hline
\end{tabular}

- My Lab and Mastering only records $100 \%$ of the grade when students enter the correct solution. For final grading per question, the student must show their solution process on the given scratch paper.

- The course also includes well-defined expectations on every assessed activity by establishing clear criteria using rubrics for all evaluated activities (see Table 5). For the midterms and final exam, each section of each problem will be evaluated respecting the following criteria.

- The grade will be adjusted by the instructor, and points will be added to the grade for work shown in the scratch paper following the criteria table. 
Table. 5 Grading Rubric

\begin{tabular}{|l|c|}
\hline Criteria & Grade \\
\hline \begin{tabular}{l|c} 
The methodology is selected correctly, with correct equations and final solution \\
is presented on the scratch paper and entered correctly in My Lab and Mastering.
\end{tabular} & $100 \%$ \\
\hline $\begin{array}{l}\text { The methodology is selected correctly and shown on the scratch paper, with } \\
\text { correct equations, only the solution of the equations is missing. }\end{array}$ & $75 \%$ \\
\hline $\begin{array}{l}\text { The methodology is selected correctly and shown on the scratch paper, equations } \\
\text { are presented incorrectly but with some merits. }\end{array}$ & $50 \%$ \\
\hline $\begin{array}{l}\text { Only Correct FBD is presented, all forces are shown and labeled, or incomplete } \\
\text { methodology selected and shown on the scratch paper. }\end{array}$ & $25 \%$ \\
\hline $\begin{array}{l}\text { Incorrect FBD or no recognized methodology is presented or it is very difficult } \\
\text { to follow solution or no work is shown on the scratch paper. }\end{array}$ & $0 \%$ \\
\hline
\end{tabular}

\section{Methodology and Data collection}

The authors used a mixed methods approach. The quantitative review was based on students' performance and students' SPOT survey. The qualitative review was based on students' comments and QM external reviews comments.

Four data sources were used to analyze the course:

1. Students' grades from first and second midterm, final exams, assignments and final grades from the fall 2018 (44 students), spring 2019 (69 students), summer 2019 (78 students), and fall 2019 (50 students) Online courses and same data for F2F course for fall 2019 (53 students).

2. Student Perception of Teaching Surveys (SPOTS) results from the same terms mentioned above. This Survey is mandatory and administrated by our Institution, is composed of nineteen questions. Eight original questions (Q1, Q2, Q8, Q9, Q10, Q12, Q13, \& Q15) were established by Chancellor's Memorandum, CM-95-06. The remaining eleven questions were designed by our Institution. The maximum grade for every question is 5 .

3. Midterm Survey collected for the spring and fall 2019 terms, this survey was prepared by the instructor with the purpose of giving the students an opportunity to reflect on their exam performance, by asking them about the self-perception preparedness for the assessment, the use of different resources and tools provided in the course and additional comments on what is going well and how the course may be improved.

4. Results and recommendations from the Quality Matters Review Final Report. 


\section{Results}

\section{Quantitative evaluation of the course}

As shown in figure 4a, performance has been steadily increasing, from a $52 \%$ passing grade in fall 2018 to a $71 \%$ passing grade in fall 2019. There was a slight drop in the passing rate between terms spring 2019 and summer 2019 (59\% vs 57\% ), but still the final exam grades show an steady increase every term (Figure $4 b$ ). Considering this course to be a core course in which historically students struggle in grasping all concepts, the results are acceptable. Of course, the instructor expectation is to increase the passing rate percentage even more.

Figure 5 shows the average of Student Perception of Teaching (SPOTs) over a maximum score of five, the same four terms are compared (from fall 2018 to fall 2019). This comparison also reflects a steady enhancement of the online course according to the student's perception. The best instructor performance, according to students, was summer 2019, which may suggest that even though the passing rate was not as expected, the students recognized the difficulty they have in grasping all the concepts in less time and acknowledging the effort made to create a course oriented to providing adequate learning support.

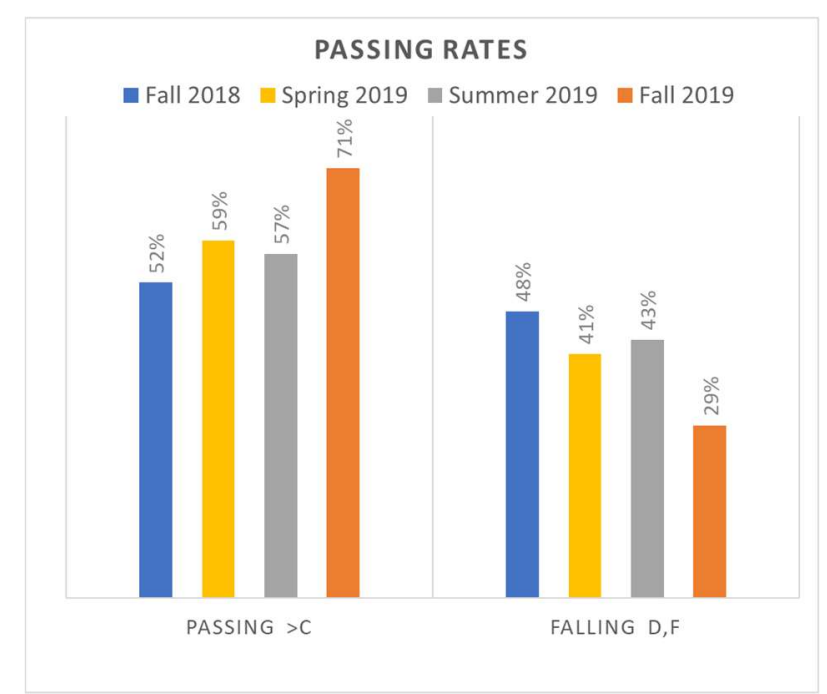

a) Passing rate

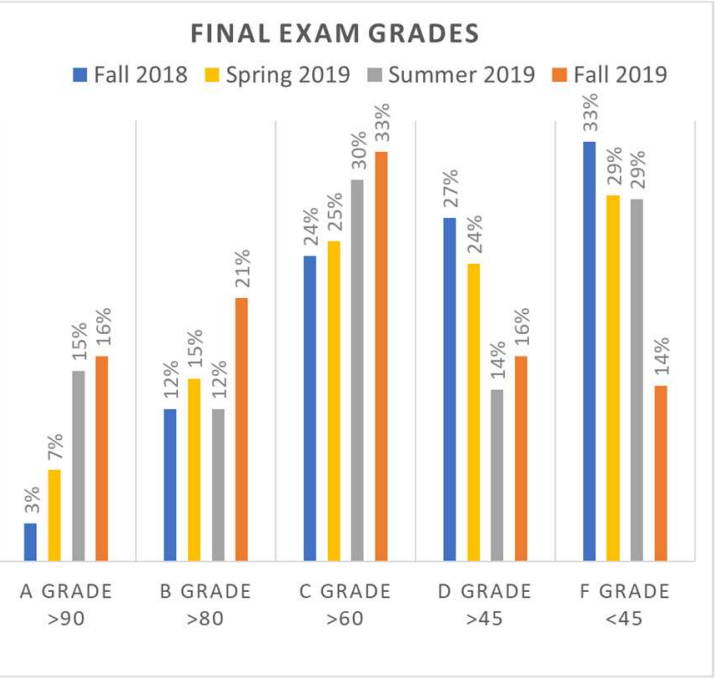

b) Final exam grades percentages.

Figure 4 Performance comparison for four consecutive terms between Fall 2018 and Fall 2019 


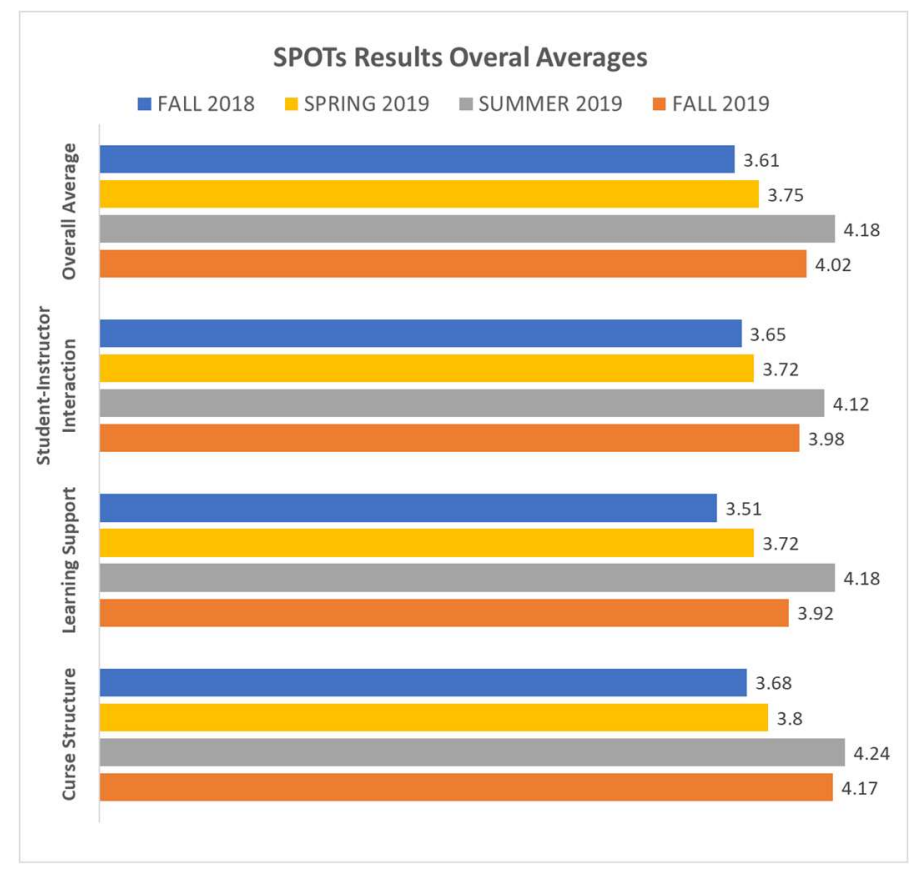

Figure 5. SPOTs quantitative results for the online dynamics course, comparison of four consecutive terms between Fall 2018, Spring 2019, Summer 2019 and Fall 2019

To best review the degree of relationship between 15 aspects of students 'perception vs students' performance, the authors used Pearson Test to review the correspondence for different students' perceptions and passing rate of the online courses. The 15 questions asked in the SPOTS are the following: 1) Description of course objectives and assignments, 2) Expression of expectations for performance in this class, 3) Description of grading policies in the course syllabus, 4) Consistency in following the course syllabus, 5) Preparation for class, 6) Use and management of class time, 7) Knowledge of course content, 8) Communication of ideas and information, 9) Stimulation of interest in course, 10) Facilitation of learning, 11) Provide feedback about your performance, 12) Availability to assist students in or out of class, 13) Respect and concern for students, 14) Fairness of instructor, 15) Overall assessment of instructor Table 8 a) and b) include the students' perceptions on SPOTS survey and its relationship with the passing rate. Highest correlated students' responses were the with questions 11) ability of the instructor to provide students' performance feedback (0.902) and 14) students' perception on instructor's fairness $(0.904)$ 
Table 8. Pearson Correlation coefficient between a) first 8 SPOTS students' perception responses and b) second 7 questions and overall SPOT average, vs passing rate in the online sections of this course.

\begin{tabular}{|c|c|c|c|c|c|c|c|c|c|c|}
\hline \multicolumn{10}{|c|}{} & \multicolumn{9}{|c|}{ SPOTS Question Numbers } \\
\hline TERM & $\mathbf{1}$ & $\mathbf{2}$ & $\mathbf{3}$ & $\mathbf{4}$ & $\mathbf{5}$ & $\mathbf{6}$ & $\mathbf{7}$ & $\mathbf{8}$ & $\begin{array}{c}\text { N students } \\
\text { Enrolled }\end{array}$ \\
\hline Fall 18 & 3.79 & 3.63 & 3.63 & 3.96 & 3.45 & 3.57 & 3.83 & 3.29 & 42 \\
\hline Spring 19 & 3.8 & 3.88 & 3.71 & 3.8 & 4.18 & 3.88 & 3.72 & 3.96 & 69 \\
\hline Sum 19 & 4.38 & 4.24 & 4.27 & 4.42 & 4.35 & 4.04 & 4.23 & 4.04 & 78 \\
\hline Fall 19 & 4.27 & 4.19 & 4.09 & 4.29 & 4.28 & 4.32 & 4.41 & 4.16 & 49 \\
\hline $\begin{array}{l}\text { Correlation } \\
\text { with Passing } \\
\text { Rate }\end{array}$ & $\mathbf{0 . 3 9 4}$ & $\mathbf{0 . 5 4 0}$ & $\mathbf{0 . 3 3 9}$ & $\mathbf{0 . 2 6 0}$ & $\mathbf{0 . 5 4 7}$ & $\mathbf{0 . 8 5 5}$ & $\mathbf{0 . 6 2 1}$ & $\mathbf{0 . 6 9 8}$ & \\
\hline
\end{tabular}

a)

\begin{tabular}{|c|c|c|c|c|c|c|c|c|c|c|}
\hline TERM & $\mathbf{9}$ & $\mathbf{1 0}$ & $\mathbf{1 1}$ & $\mathbf{1 2}$ & $\mathbf{1 3}$ & $\mathbf{1 4}$ & $\mathbf{1 5}$ & $\begin{array}{c}\text { SPOT } \\
\text { Average }\end{array}$ & $\begin{array}{c}\text { Passing } \\
\text { rate }\end{array}$ \\
\hline Fall 18 & 3.48 & 3.46 & 3 & 3.67 & 3.83 & 3.54 & 3.54 & 3.6 & $52.4 \%$ \\
\hline Spring 19 & 3.68 & 3.46 & 3.54 & 3.31 & 3.79 & 3.88 & 3.52 & 3.7 & $59.4 \%$ \\
\hline Sum 19 & 3.96 & 4.04 & 3.46 & 3.92 & 4.04 & 3.88 & 4.08 & 4.1 & $55.2 \%$ \\
\hline Fall 19 & 4.04 & 4.04 & 3.87 & 4.02 & 4.26 & 4.17 & 4.04 & 4.2 & $71.4 \%$ \\
\hline $\begin{array}{l}\text { Correlation } \\
\text { with Passing } \\
\text { Rate }\end{array}$ & $\mathbf{0 . 6 8 5}$ & $\mathbf{0 . 5 1 1}$ & $\mathbf{0 . 9 0 2}$ & $\mathbf{0 . 3 8 7}$ & $\mathbf{0 . 7 6 5}$ & $\mathbf{0 . 9 0 4}$ & $\mathbf{0 . 4 6 1}$ & $\mathbf{0 . 6 5 8}$ & \\
\hline
\end{tabular}

b)

The course dynamics EGN3321 was delivered by the same instructor (author of this paper) on a regular F2F class for the first time during the fall 2019 using the same material and examples. Figure 6 shows the one-term comparison between online and F2F course delivery. The online course was delivered with videos as described in the previous sections and the in F2F version, the problems were solved in class with the students. Assignments and exams were the same and the exams were taken the same day in combined computer labs, all in person. Only five of the online students took the exams the same day at the same time in a proctored testing center at a different institution. The data show that grades for the online version of the course were slightly lower than the one delivered F2F and the average final grade was also lower. In contrast, the 
SPOTs were higher for the online course in comparison with the F2F version of the course in all aspects of the survey but differed in the interaction between instructor and student, suggesting that students appreciate the course structure and learning support provided.

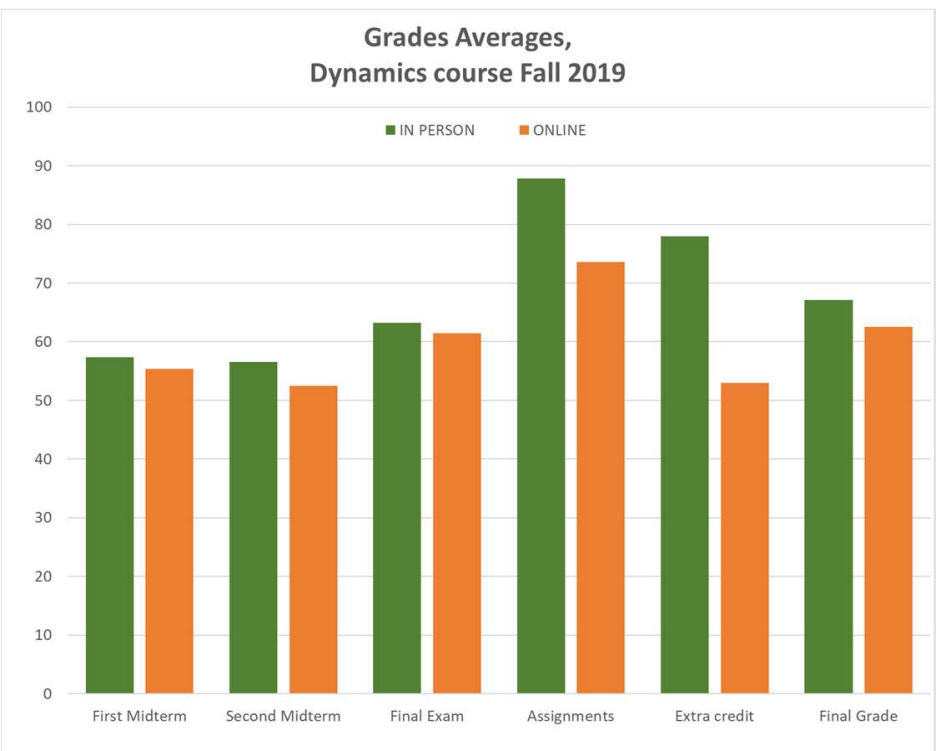

a) Average grades

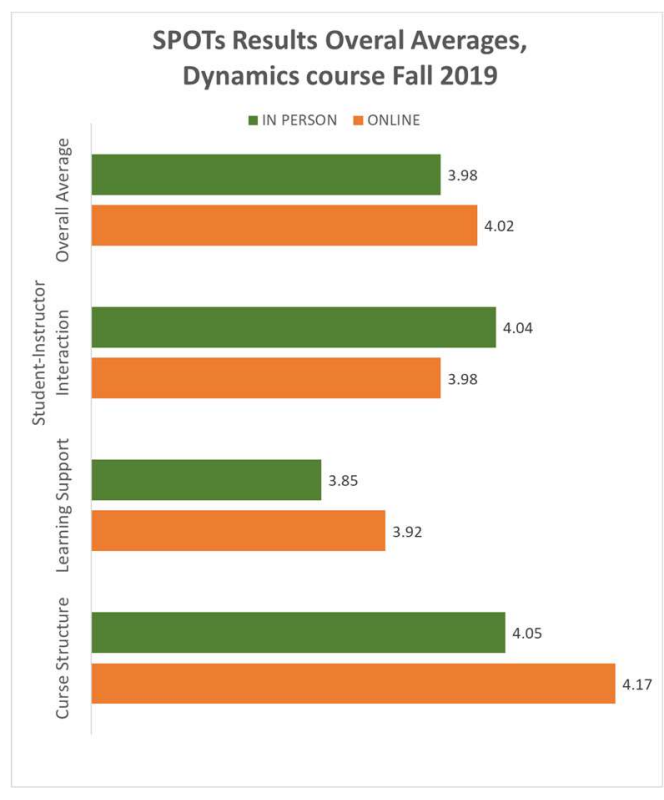

b) SPOTs results

Figure 6. Performance comparison between Dynamics Online and Face to Face sections for fall 2019. a) Average grades for exams and assignments, b) Student Perception of Teaching In the midterm survey, performance benchmarks were established to determine whether students met the Course Objectives (COs). This survey was delivered to the students in the spring and fall 2019 terms. Each exam question had rubric criteria related to the COs and the instructor would provide as needed relevant feedback based on the COs attainment level by the student. Figure 7. Shows similarities in the self-reported preparedness or student perception of their level of understanding for the different topics and COs to be assessed in the first exam (Modules 1, 2 and 3) for both F2F and online versions of the course. The results show that in most of the topics, student reported to be either very well prepared or somewhat prepared (together about 60\%). A grade point was given to the student's perceptions on their level of understanding as selfreported in the survey and these results were compared with the actual grade obtained by the 
students in the assessment. The comparison showed that more than $66 \%$ of the students' perceptions were aligned with their test scores.

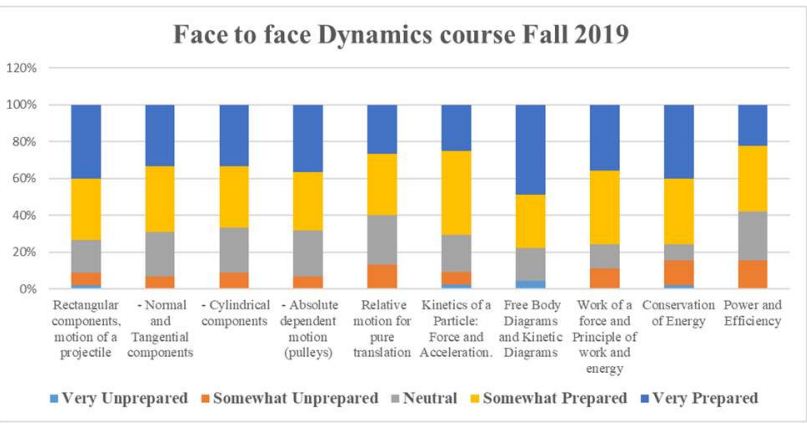

a) Face-to-face course

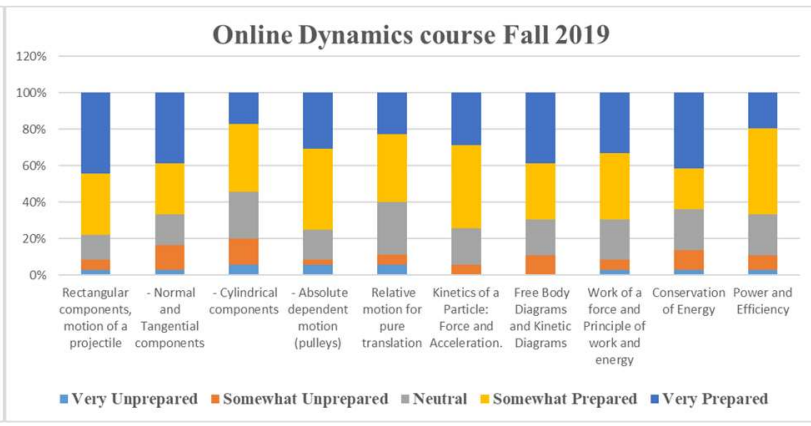

b) Online course

Figure 7. Comparison between Dynamics Online and Face-to-Face sections in student selfreported preparedness in learning objectives to be assessed in first exam

\section{Qualitative evaluation of the course}

Students' comments taken from the SPOTs; Fall2018: "I really enjoy watching Dr. Muller videos on Canvas because they were a great resource to learn. The videos are short but give all the information necessary to learn. She also has extra videos working on problems that help in learning”. Spring2019: "The example videos have been very helpful with how they provided clear visualizations of the concept being taught as well as explanations of the approaches available to get the solutions. The narrated lectures have been very helpful too because the professor provided little extra bits of information to further clarify some elements that could've confused the student". Summer2019: “The videos were very well done and easy to follow. The use of different colors facilitated the comprehension of the examples". Fall 2019: "Great class for heavy learning. Requires a lot of dedication, time, and effort", "Great professor. She is always able to help all students and she always try to be a best professor. Thank you", "It was a very interesting class that I would recommend to any student."

The course follows ABET criteria and has been accredited by Quality Matters ${ }^{\mathrm{TM}}$ in 2019 . The QM review process was held by an external committee of three members where one was a Subject Matter Expert, receiving an initial score of 97/100 and after fulfilling the requirement of enhancing the rubrics, the course was certified with a perfect score 100/100. 


\section{Conclusion}

In this paper we describe the development of a Dynamics Online course, its delivery for four consecutive terms and the quantitative and qualitative assessment using different sources of data. To develop the course, we chose granular structure recording videos using high end instructional resources. Each module containing single concepts videos of theoretical background followed by several single example videos solving key problems. The alignment of critical course components was a priority, once the students learning outcomes were stablished, the learning activities and different assessments to measure the learning process where designed. During the studied period (fall 2018, spring 2019, summer 2019 and fall 2019), student performance has been steadily improving and so has the student perception of the course. The results of Pearson test to correlate the student perception in relation to the passing grade, show that fairness of the instructor was one of the variables with higher value, we could infer that students find helpful the well described rubrics for each assessment.

This paper has offered additional proof that developing and delivering at a distance a Dynamics course, using instructional design best practices, is equivalent to a F2Fcourse as reflected by the student outcomes and perceptions.

\section{Reference}

[1] J. Bourne, D. Harris and F. Mayadas, "On-Line engineering education: Learning anywhere, anytime," Journal of Engineering Education, 2005.

[2] S. Huang and J. Mativo, "Impact of interventions on students' conceptual understanding of dynamics, principles and self-efficacy.," in ASEE, Paper \#12469, Seattle, WA, 2015.

[3] L. G. Gary, F. Constanzo, D. Evans, P. Cornwell, B. Self and J. L. Lane, "The Dynamics Concept Inventory Assessment Test: A Progress Report and Some Results," in ASEE, Portland, OR, 2005.

[4] M. G. Morgan, "Theory of transactional distance.," in Keegan, D. (Ed.), Theoretical principles of distance education. , NY, Rotledge, 1993, pp. 22-38.

[5] Y. Chen, "Transactional distance in World Wide Web learning environments.," in Innovations in Education and Teaching International, 2001, pp. 327-338.

[6] K. W. Tunks, " An introduction and guide to enhancing online instruction with web 2.0 tools.," Journal of Educators Online 9, 2012.

[7] A. Purwar and C. A. Scott, " An Online Engineering Dynamics Class for College Sophomores: Design, Implementation, and Assessment," in ASEE, Tampa, FL, 2019. 
[8] D. Baker, "Colorado State University Online," [Online]. Available: https://www.online.colostate.edu/courses/CIVE/CIVE261.dot. [Accessed November 2018].

[9] Virginia Western College, "EGR 245 Engineering Mechanics - Dynamics," [Online]. Available:

https://catalog.virginiawestern.edu/preview_course_nopop.php?catoid=2\&coid=898. [Accessed March 2019].

[10] ABET, " Criteria 3. Student Outcomes," [Online]. Available:

https://www.abet.org/accreditation/accreditation-criteria/criteria-for-accreditingengineering-programs-2019-2020/\#GC3. [Accessed January 2020].

[11] G. Wiggins and J. McTighe, The Understanding by Design Guide to Creating High Quality Units, Alexandria, VA: ASCD, 2011.

[12] R. C. Hibeller, Engineering Mechanics: Dynamics, Pearson 14th Ed., 2016.

[13] Quality Matters, "Standards from the Quality Matters Higher Education Rubric, 6th Edition.," [Online]. Available: https://www.qualitymatters.org/sites/default/files/PDFs/StandardsfromtheQMHigherEduca tionRubric.pdf .. [Accessed January 2020].

[14] CANVAS. [Online]. Available: https://www.instructure.com/canvas/ . . [Accessed January 2020].

[15] "ExplainEverything (TM),," [Online]. Available: https://explaineverything.com/, . [Accessed January 2020].

[16] L. W. Anderson, D. R. Krathwohl, P. W. Airasian and K. A. Cruikshank, A Taxonomy for Learning, Teaching, and Assessing: A Revision of Bloom's Taxonomy of Educational Objectives, NY: Longan, 2001.

[17] D. Lewis and J. Slapak-Barski, "The Faculty Toolbox: A tool for promoting faculty use of Instructional Technologies.," in Society for Information Technology \& Teacher Education International Conference, Chesapeake, VA, 2014.

[18] R. C. \&. M. R. Clark, Elearning and the Science of Instruction., San Francisco, CA: Pfeiffer, 2011.

[19] M. G. Moore, "Theory of transactional distance," in In Keegan, D. (Ed.), Theoretical principles of distance education, NY, Routledge, 1993, pp. 22-38. 